\title{
Communication Preference and the Effectiveness of Clickers
}

\author{
Raymond Li \\ School of Accounting and Finance Hong Kong Polytechnic University
}

\begin{abstract}
In this project a web-based classroom response system ("clickers") was used in the teaching an intermediate level economics course. Clickers gives students a chance to respond to the instructor's question privately, encouraging students who might not typically speak up in class to express their thoughts and opinions. The purpose of this project is to (1) find out if the use of clickers is beneficial to students taking economics, and (2) examine if students' communication preference (e.g. instant messaging, face-to-face conversations, etc.) has an impact on the effectiveness of clickers in improving learning outcomes. An end-of-semester questionnaire and students' examination performance were used to assess the effectiveness of clickers in this project. According to the questionnaire results, around $75 \%$ of the students in the treatment (clickers) group generally agreed that clickers allowed them to express their views more freely. We also observed that students who prefer to use instant messaging rather than making conversations are generally more positive towards clickers. The use of clickers also benefits the instructor - students' rating of the instructor in the teaching evaluation was significantly higher for the clickers treatment group. Comparing the examination scores of the clickers treatment group and control group, the treatment group performed considerably better and statistically significant differences were found basing on paired t-tests on the differences. Our regression analysis further discovered that the use of clickers has the most significant positive effect on students who prefers to communicate through instant messaging.
\end{abstract}

Keywords: clickers; student attributes; communication preference; economics education. 